\title{
Cognitive and Sleep Features of Multiple System Atrophy: Review and Prospective Study
}

\author{
Michelangelo Stanzani-Maserati ${ }^{a, b}$ Roberto Gallassi ${ }^{a}$ \\ Giovanna Calandra-Buonaura $^{a, b}$ Maria Alessandria ${ }^{a, b}$ Federico Oppi ${ }^{a}$ \\ Roberto Poda $^{a}$ Luisa Sambatia, Federica Provini ${ }^{a, b}$ Pietro Cortellia, $b$

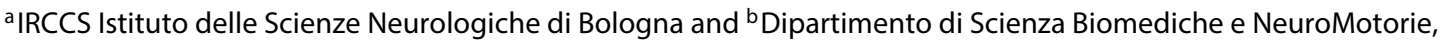 \\ Università di Bologna, Bologna, Italy
}

\section{Key Words}

Cognitive neurology $\cdot$ Dementia $\cdot$ Neuropsychology ·

Parkinsonism $\cdot$ Sleep disorders

\begin{abstract}
Background: The profile and degree of cognitive impairment in Multiple System Atrophy (MSA) and the impact of sleep disorders, REM sleep behavior disorder (RBD) in particular, in parkinsonism-related cognitive deficits are currently being debated. Summary: We reviewed the cognitive, affective and sleep findings in MSA and also carried out a longitudinal investigation of 10 MSA patients. At the first evaluation, 3 patients showed isolated cognitive deficits. After a mean of 16 months, these patients remained unchanged, while 1 patient worsened from a normal condition. No significant differences emerged when the cognitive, affective and video-polysomnographic findings of MSA-P and MSA-C were compared. Depression was present in half of the patients, although it did not influence their cognitive performance. Comparisons between the first and second evaluation data showed significant worsening in visual attention and in ADL/IADL and UMSARS. Key Messages: Isolated cognitive deficits are evidenced in a minority of MSA patients
\end{abstract}

\section{KARGER}

E-Mail karger@karger.com www.karger.com/ene with the absence of a clear-cut diagnosis of dementia in the early stages of the disease. Attention and executive functions are often impaired. This study with a short follow-up period showed that RBD, although present in almost all patients affected by MSA, does not appear a clear early marker of cognitive impairment. Future longer-term studies with a larger patient sample are thus encouraged.

(c) 2014 S. Karger AG, Basel

\section{Introduction}

Multiple system atrophy (MSA) is a sporadic, adultonset, progressive neurodegenerative disease characterized clinically by parkinsonism, cerebellar ataxia, autonomic failure, and corticospinal signs with poor or no response to levodopa, and pathologically by cell loss, gliosis, and glial cytoplasmic inclusions in several neural cell systems (striatonigral, olivopontocerebellar, autonomic) [1].

The analysis of cognitive functions in MSA has gained interest and the related profile and degree of cognitive impairment along the course of the disease is yet a subject of debate. The presence of dementia, particularly at onset,
(C) 2014 S. Karger AG, Basel

0014-3022/14/0726-0349\$39.50/0
Michelangelo Stanzani-Maserati

IRCCS Istituto delle Scienze Neurologiche di Bologna via Altura 3, 40139 Bologna (Italy)

E-Mail michelangelo.sm@libero.it 
is a not supporting feature to the diagnosis of MSA. We reviewed literature about this topic and matched it with sleep disorders data in MSA. In fact, sleep disorders, and REM sleep behavior disorder (RBD) in particular, have often been involved in parkinsonism-related cognitive deficits [3-5]. We also investigated longitudinally cognitive functions and sleep characteristics in a group of probable MSA patients.

\section{Review on Cognitive Impairment in MSA}

\section{Cognitive Deficits}

MSA patients display a milder degree of cognitive impairment with respect to corticobasal degeneration, progressive supranuclear palsy (PSP) and Lewy body dementia (LBD). With respect to PD without dementia, not definite differences seem to emerge [6-15].

Heterogeneous cognitive dysfunctions in MSA have been reported by many authors $[6-8,14-33]$. The executive functions are described as the most frequent impaired abilities but other cognitive domains that can be involved are memory, visuospatial, and constructional functions. Brown et al. [7] in a large cohort of MSA patients found that approximately two-thirds of subjects showed no significant cognitive impairment. In a single cognitive domain, impairment was found in $28.6 \%$, while in two or more domains, it was present in $13.5 \%$ and global cognitive impairment was observed in $11-32 \%$ of patients. Cognitive impairment was predicted by factors like greater motor disability, educated for less than 10 years, male gender, and the presence of cardiovascular dysautonomia. It is however noteworthy that in the cognitive impaired group, the diagnosis was further pathologically confirmed in $64.4 \%$ of cases, while a final diagnosis of PSP, LBD or amyotrophic lateral sclerosis was ascertained in the remaining cases; in the unimpaired group, the diagnosis of MSA was confirmed in $94.6 \%$ of cases.

Dementia was recently reported by some authors [16, $17,22,23,34,35]$. Wenning et al. [34] in a retrospective, pathologically confirmed case study, showed that dementia was detected in $15.7 \%$ of a sample of 38 MSA cases and in none of them dementia onset was reported within the first 5 years. In another study [35], 14\% of a sample of 83 pathologically confirmed cases were identified as demented. Finally, in a recent cross-sectional multicenter study, Siri et al. [17] did not find general cognitive decline in the first 5.7 years of the disease but a selective impairment in executive functions.

\section{Evolution of Cognitive Deficits}

Soliveri et al. [6] investigated a group of 14 patients affected by striatonigral degeneration-type of MSA (SND), according to Quinn's criteria [36]. At the first evaluation, the MSA patients showed a significant deficit in a test of verbal fluency when compared with a group of PD patients. After a mean of 21 months follow-up, patients did significantly worse on a visual search test. No patients were clearly demented at either evaluation. Lyoo et al. [25], analyzing the progression of MSA by PET and neuropsychological examination in MSA patients with different disease duration, found that patients with a shorter disease duration showed executive and verbal memory dysfunctions, while patients with longer disease duration had multiple-domain cognitive impairment, including visuospatial deficits.

\section{Difference of Cognitive Deficits between \\ $M S A-P$ and $-C$}

Kawai et al. [24] compared 21 MSA-P with 14 MSA-C patients. In respect to controls, the MSA-P patients showed involvement of visuospatial and constructional function, verbal fluency, and executive functions, while the MSA-C patients were impaired only in visuospatial and constructional functions with a milder degree of involvement compared with MSA-P patients. These data suggest a more severe and widespread impairment in MSA-P patients, despite similar disease duration. Other studies $[8,9,15]$ obtained heterogeneous and even conflicting data. Bak et al. [9], in fact, did not find visuospatial impairment in a group of MSA-P patients of long disease duration and evidence of other cognitive domains impairment. These data are consistent with those of Robbins et al. [15] on a group of MSA-P patients and with those of Bürk et al. [26] on an MSA-C sample. On the contrary, Kao et al. [8] confirmed the presence of visuospatial deficits in an MSA group of patients. Siri et al. [17] did not find significant cognitive differences between the two subtypes of MSA.

\section{Neuropsychiatric Symptoms}

Kao et al. [8] described depression in $50 \%$ of patients of a group of MSA subjects, anxiety in $33.3 \%$ and disinhibition in $10 \%$. Schrag et al. [20] confirmed these data, while Kawai et al. [24] and Brown et al. [7] found a smaller prevalence of depression (about 21-22\%) and Chang et al. [23] confirmed a significant presence of anxiety in a group of MSA-C patients. Balas et al. [19] also made the analysis of the impact of mood, anxiety and depression, on cognitive functions of an MSA group of subjects com- 
pared with the controls and PD patients. The MSA-P and PD patients had significant greater state anxiety, trait anxiety, and depression than did controls, and the MSA$C$ patients had significant increased state anxiety compared to controls. These authors conclude that anxiety and depression are related to cognitive decline. Recently, Siri et al. [17] found that depression was more frequent in MSA group than in PD and it correlated with motor symptoms, but it did not show a significant influence on cognitive performances in all groups.

\section{Pathogenetic Mechanisms of Cognitive Deficits}

Kawai et al. [24] found that the severity of cognitive impairment in MSA-P patients correlated with a hypoperfusion in the dorsolateral prefrontal cortex. Frontal cortical atrophy has been detected bilaterally in MSA-C by means of a voxel-base morphometry study together with bilateral cerebellum gray matter reduction [23]. Lyoo et al. [25] found that hypometabolism started from the frontal and cerebellar regions, sparing the basal ganglia in the less-than-one-year disease-duration group, while patients with longer duration showed hypometabolism in more widespread cerebral cortical areas involving the frontal, temporal, parietal and cingulate cortices. The hypometabolism is supposed to be caused by the diffusion of glial cytoplasmatic inclusions than by cortical loss, especially in the first phases of the disease. A progressive alteration of the afferent cortical inputs is also supposed to arise from the subcortical nuclei (e.g., locus coeruleus and substantia nigra), thus linking the subcortical and cortical structures.

The effect of orthostatic hypotension on cognitive function in MSA is still controversial [16, 21, 37-39]. Also, the correlation between MMSE, Frontal Assessment Battery and the values for oxygen saturation, apnea index, and apnea-hypopnea index during sleep has not been found [21].

\section{Review on Sleep Disturbances in MSA}

\section{Sleep-Related Complaints}

A clinical questionnaire-based study by Ghorayeb et al. [40] showed that $70 \%$ of MSA patients significantly complained of sleep disorders when compared to $51 \%$ of patients with PD. Sleep fragmentation was reported by $53 \%$ of patients as the most frequent complaint followed by early waking (33\%) and insomnia (20\%) with no significant difference in PD patients. Excessive daytime sleeping has also been reported according to Ghorayeb et

Cognitive and Sleep Features of Multiple

System Atrophy al. [41] in half of the MSA patients, while Moreno-Lopez et al. [42] has recently reported it in $28 \%$ of patients with MSA, weakly correlated with disease severity and not correlated with the amount of dopaminergic treatment.

\section{Sleep Structure}

Polysomnographic studies reported that the total sleep time and sleep efficiency reduced and wake after sleep onset increased [43-47]. Vetrugno et al. [44] found that sleep stages 1 and 2 were increased, while stages 3 and 4 decreased; however, REM sleep was normal. Plazzi et al. [46] found sleep stage percentages unchanged with respect to a whole group of MSA patients. But individual variations in sleep stage percentages were described by Nam et al. [43] in a study designed to eliminate the major confounding variables of sleep such as obstructive sleep apneas (OSA), periodic limb movements during sleep (PLMS) and the influence of anti-parkinsonian medications. These authors conclude that MSA by itself does not affect the sleep structure because even the analysis of the microstructure (i.e., sleep instability) compared with controls shows no differences in every aspect, including cycling alternating pattern (CAP rate, CAPs A and $B$, and non-CAP). However, this topic is still a matter of debate because Vetrugno et al. [48] had shown a significantly lower CAP rate in a group of MSA patients compared to a group of patients with primary restless legs syndrome.

\section{Sleep-Related Respiratory Abnormalities}

Nocturnal stridor and OSA have been extensively reported as the most common sleep-related breathing disorders in MSA patients [40,41, 44, 46, 47]. The prevalence of nocturnal stridor (a strained, high-pitched, harsh respiratory sound) varies from $13 \%$ to $69 \%[49,50]$. In one study, stridor was more frequently detected in MSA$\mathrm{C}$ than in MSA-P patients [44], but the contrary was also shown [41]. OSA ranges from $15 \%$ to $37 \%$ [44-46] and may contribute to mild $\mathrm{O}_{2}$ desaturation occurring during sleep in MSA. However, the relationship between nocturnal respiratory abnormalities and cognitive performance has not been specifically investigated yet.

\section{Periodic Limb Movements during Sleep}

PLMS are frequently reported in polysomnographic studies on MSA [43-46, 48]. They are significantly increased respect to control $[45,46,48]$, and may contribute to sleep fragmentation and reduced sleep efficiency. Restless legs syndrome, in a questionnaire-based study, occurred in $28 \%$ of patients with MSA, doubling the fre- 
quency occurred in PD patients (14\%) and 4 times more frequent than in the control group (7\%) and unrelated to the amount of dopaminergic treatment [44].

\section{$R B D$}

RBD is the most common sleep-related disorder in MSA [40, 41, 44, 46, 51, 52] and may precede the development of parkinsonism by years [45, 52-54]. Current knowledge indicates that up to $81-82 \%$ of patients with idiopathic RBD develop a parkinsonian disorder $[55,56]$. Ninety to $100 \%$ of MSA patients have polysomnographicconfirmed RBD, and clinical symptoms of RBD precede the onset of MSA by more than 1 year in $44 \%$ of the patients evaluated [44, 46]. Comparing RBD in MSA and PD, Iranzo et al. [57] showed that patients with MSA, compared to subjects with $\mathrm{PD}$, had a higher REM sleep without atonia percentage, and, if compared with those with idiopathic RBD, an onset of RBD at a younger age with a less awareness of their abnormal sleep behaviours. Authors suggest that in MSA there could be a more severe dysfunction in the structures that modulate REM sleep. Vetrugno et al. [51] described similar pathogenetic mechanisms about the natural evolution of RBD in the socalled status dissociatus, a more complex and pervasive sleep disturbance with a sleep pattern disruption where the stages can no longer be identified.

\section{The Prospective Study}

\section{Patients and Methods}

Ten consecutive in-patients, fulfilling the criteria for probable MSA [1], were evaluated in our Neurological Department in a two-year period. All subjects gave their informed consent to the study according to the Declaration of Helsinki.

All patients underwent a detailed interview, checked with interviews of close relatives, and a general and neurological examination, including the application of the UMSARS [58]. Patients were also investigated by blood tests, cerebral MRI scans, and by means of a cardiovascular reflexes study. An extensive battery of neuropsychological tests, standardized in the Italian population, exploring global cognition and different cognitive functions was administered (table 1) [59-72]. We evaluated depression with the Beck Depression Inventory (BDI) [73] and anxiety using the State-Trait Anxiety Inventory-Form $\mathrm{Y}$ (STAI) [74]. An all-night video-polysomnography recording (VPSG) was acquired and sleep was scored according to the American Academy of Sleep Medicine
(AASM) criteria [75]. RBD, defined according to International Classification of Sleep Disorders [76], was checked against the video-recordings. Sleepiness was assessed by Epworth Sleepiness Scale [77].

All patients were re-evaluated (T1) in a mean of $16.1 \pm$ 5.5 (range: 12-28) months after the initial evaluation (T0). At the second evaluation (T1), the neuropsychological assessment and video-polysomnography were repeated.

\section{Statistical Analysis}

Data were analyzed using the SPSS statistical analysis software, version 19.0. We performed a descriptive analysis of the various parameters of patients, considering the normal values of the normative data. Some variables being non-normally distributed, non-parametric tests were employed: test U of Mann-Whitney for comparison of patients' performance between groups (MSA-P versus MPA$\mathrm{C}$, no depressed versus depressed patients, shorter duration versus longer duration patients), Wilcoxon test for correlated samples for comparisons between T0 and T1 performance, Kendal Tau for correlation among cognitive performances, clinical variables and polygraphic data.

\section{Results}

Seven men and 3 women were enrolled. Six had probable cerebellar type MSA (MSA-C) (4 men) and four had probable parkinsonian type MSA (MSA-P) (3 men). The overall mean age was $57.8 \pm 6.4$ (range: $47-64$ ) with a mean education of $10.7 \pm 4.5$ years (range: $5-17$ ). The mean age at disease onset was $53.2 \pm 7.1$ (range: 43-61) and symptoms duration at $\mathrm{T} 0$ was $60 \pm 48$ months (range: 12-144). MSA-P in respect to MSA-C had a higher age $(61.75 \pm 0.94$ vs. $55.17 \pm 2.94$ years), lower education $(8.75 \pm 2.83$ vs. $12.00 \pm 1.41$ years $)$ and shorter symptoms duration ( $27.00 \pm 7.55$ vs. $82.00 \pm 20.64$ months). Only symptoms duration is significantly different $(p=0.03)$. RBD was present in all patients with a mean age at onset of $53.4 \pm 7.3$ (range: $40-61$ ).

\section{Neuropsychological and Affective Results}

At the initial evaluation (T0), 7 patients showed no cognitive deficits, while 2 patients (MSA-C) had a long-term verbal memory deficit and 1 patient (MSA-P) had deficit in visuospatial tasks (table 2). Considering the global cognitive indexes for each patient (MMSE and BMDB Final Result) and daily living activity, no patient could be stated demented. At T0, the mean values of all tests in the whole group were within normal range, while the mean values of 
Table 1. Neuropsychological tests and assessment of anxiety and depression

\begin{tabular}{|c|c|}
\hline Cognitive functions & Test \\
\hline $\begin{array}{l}\text { Global cognitive } \\
\text { functions indices }\end{array}$ & $\begin{array}{l}\text { MMSE (range: 0-30) (Folstein et al., 1975), MMSE corrected for age and education (range: 1.93-35.24; } \\
\text { cut-off: <23.8) (Measso et al., 1993) } \\
\text { Brief Mental Deterioration Battery (BBDM) with Final Result (FR) (cut-off: <0) (Gallassi et al., 1986, } \\
\text { 2010) }\end{array}$ \\
\hline Memory & $\begin{array}{l}\text { Rey's } 15 \text { Words: immediate recall (range: 0-75; cut-off: <28.53); delayed recall (range: 0-15; cut-off: } \\
<4.69) \text { (Carlesimo et al., 1996) } \\
\text { Paired-associated Word Learning Test (range: 0-22.5; cut-off: <8.73) (De Renzi et al., 1977) } \\
\text { Immediate Visual Memory (range: 0-22; cut-off: <13.85) (Carlesimo et al., 1996) } \\
\text { Digit Span Forward (range: 0-9; cut-off: <3.75) (Orsini et al., 1987) } \\
\text { Corsi Block-tapping Test (range: 0-infinite; cut-off: <3.75) (Spinnler and Tognoni, 1987) } \\
\text { Rey-Osterrieth Complex Figure Test: delayed recall (range: } 0-36 \text {; cut-off: <6.20) (Caffarra et al., 2002) }\end{array}$ \\
\hline Attention & $\begin{array}{l}\text { Barrage Test (time cut-off: } \geq 90 \text {; score cut-off: } \leq 9 \text {; errors cut-off: } \geq 2 \text {; result cut-off: }>2.5 \text { ) } \\
\text { (Gallassi et al., 1986, 2002) } \\
\text { Stroop Test (time cut-off: }>27.5 \text {; errors cut-off: }>7.5 \text { ) (Caffarra et al., 2002) } \\
\text { Trail Making Test (A cut-off: }>93 \text {; B cut-off: }>283 \text {; B-A cut-off: }>187 \text { ) (Giovagnoli et al., 1996) }\end{array}$ \\
\hline Language & $\begin{array}{l}\text { Verbal Fluency: phonemic (range: 0-infinite; cut-off: <17.35) (Carlesimo et al., 1996); semantic (range: } \\
\text { 0-infinite; cut-off: <25) (Novelli et al., 1986) }\end{array}$ \\
\hline Constructional praxis & $\begin{array}{l}\text { Copy Design: simple (range: 0-12; cut-off: <7.18) (Carlesimo et al., 1996) } \\
\text { Rey-Osterrieth Complex Figure Test: direct copy (range: 0-36; cut-off: <28) (Caffarra et al., 2002) }\end{array}$ \\
\hline Visuospatial functions & Judgment of Line Orientation Test (range: 0-30; cut-off: <19) (Ferracuti et al., 2000) \\
\hline Executive functions & $\begin{array}{l}\text { Wisconsin Card Sorting Test (global score cut-off: }<90.50 \text {; perseverations cut-off: }<42.60 ; \\
\text { non-perseverative errors cut-off: }<29.90 \text {; failure to maintain the set cut-off: }<3 \text { ) (Laiacona et al., 2000) }\end{array}$ \\
\hline $\begin{array}{l}\text { Abstract/concrete } \\
\text { thinking - intelligence }\end{array}$ & $\begin{array}{l}\text { Raven Coloured Progressive Matrices (range: } 0-36 \text {; cut-off: }<18.96 \text { ) (Carlesimo et al., 1996) } \\
\text { Analogies (range: } 0-20 \text {; cut-off: <15.1) (Gallassi et al., 1986, 2002) } \\
\text { Test di Intelligenza Breve derived from the National Adult Reading Test by Nelson H.E., } 1982 \\
\text { (raw score cut-off: } \geq 19.8 \text {; total IQ cut-off: } \leq 93.1 \text { ) (Colombo et al., 2002) }\end{array}$ \\
\hline
\end{tabular}

the scales for depression and trait anxiety were slightly increased (table 3). Slight/moderate depression was present in half of the patients, in those with isolated cognitive deficits, without a difference in respect to the type of MSA ( $\mathrm{P}$ or $\mathrm{C})$, and also in those not cognitively impaired. Comparing depressed patients with those who were not depressed, no significant differences emerged in neuropsychological tasks, clinical and sleep parameters (table 2).

Comparing MSA-P and MSA-C, although MSA-C had a longer illness duration, any significant differences were detected in neuropsychological, affective and sleep variables (table 2).

Comparison between patients who had a shorter illness duration (within two years) and those who had longer ones ( $\geq 48$ months) showed that patients with a longer duration had longer RBD duration $(p=0.03)$, better per-

Cognitive and Sleep Features of Multiple System Atrophy formance in MMSEc $(p=0.02)$ and in Rey 15 words short-term $(\mathrm{p}=0.04)$.

At the second evaluation (T1), after a mean of $16 \pm$ 5 months (range: $12-28$ ) after T0, 6 patients still showed no cognitive deficits and 3 patients were cognitive unchanged, respectively showing deficits in long-term verbal memory in 2 (MSA-C) and in constructional praxis and visuospatial functions in 1 (MSA-P). Only 1 patient's (MSA-P) (patient 2) condition worsened by the development of multiple cognitive deficits from a not cognitive impaired condition (table 3 ). In this patient, global cognitive indexes were still unchanged and within normal limits. At T1, the mean values of all tests in the whole group were still within the normal range.

The comparisons between neuropsychological and affective evaluation at T1 and T0 (table 3 ) showed a signif- 
Table 2. Clinical and neuropsychological data at $\mathrm{T} 0$ and $\mathrm{T} 1$

\begin{tabular}{llllllll}
\hline $\begin{array}{l}\text { Patient/ } \\
\text { sex }\end{array}$ & $\begin{array}{l}\text { Age at } \\
\text { examination, } \\
\text { years (T0/T1) }\end{array}$ & $\begin{array}{l}\text { Education, } \\
\text { years }\end{array}$ & $\begin{array}{l}\text { MSA } \\
\text { type } \\
\text { (C/P) }\end{array}$ & $\begin{array}{l}\text { Symptoms } \\
\text { duration, years } \\
\text { (T0/T1) }\end{array}$ & Cerebral MRI & $\begin{array}{l}\text { Depression } \\
\text { (yes/no) }\end{array}$ & $\begin{array}{l}\text { Impaired cognitive functions (T0/T1) } \\
1 / \mathrm{f}\end{array}$ \\
\hline $52 / 54$ & 8 & $\mathrm{C}$ & $2 / 4$ & cerebellar atrophy & yes & T0/T1: long-term verbal memory \\
\hline $2 / \mathrm{m}$ & $59 / 60$ & 5 & $\mathrm{P}$ & $2 / 3$ & cerebellar atrophy & no & $\begin{array}{l}\text { T0: no deficit } \\
\text { T1: long-term verbal memory; short-term } \\
\text { spatial memory; visual attention; constructional } \\
\text { praxis; visuospatial tasks; verbal fluency }\end{array}$ \\
\hline $3 / \mathrm{m}$ & $47 / 50$ & 13 & $\mathrm{C}$ & $2 / 4$ & cerebellar atrophy & yes & T0/T1: long-term verbal memory \\
\hline $4 / \mathrm{m}$ & $64 / 65$ & 8 & $\mathrm{P}$ & $2 / 3$ & normal & yes & T0/T1: no deficit \\
\hline $5 / \mathrm{m}$ & $62 / 63$ & 13 & $\mathrm{C}$ & $13 / 15$ & normal & yes & T0/T1: no deficit \\
\hline $6 / \mathrm{m}$ & $48 / 49$ & 13 & $\mathrm{C}$ & $6 / 7$ & normal & no & T0/T1: no deficit \\
\hline $7 / \mathrm{m}$ & $62 / 63$ & 17 & $\mathrm{P}$ & $1 / 2$ & cerebellar atrophy & no & T0/T1: no deficit \\
\hline $8 / \mathrm{f}$ & $63 / 64$ & 5 & $\mathrm{P}$ & $5 / 6$ & bilateral putaminal & yes & T0/T1: visuospatial tasks \\
\hline $9 / \mathrm{m}$ & $58 / 59$ & 17 & $\mathrm{C}$ & $12 / 13$ & normal & no & T0/T1: no deficit \\
\hline $10 / \mathrm{f}$ & $64 / 65$ & 8 & $\mathrm{C}$ & $4 / 5$ & normal & no & T0/T1: no deficit \\
\hline
\end{tabular}

icant worsening in two tests of attention: Barrage Test (score), and Trail Making Test (A). A comparison between functional autonomy and motor performances scales disclosed a significant worsening in ADL, IADL and UMSARS (table 3).

A significant positive correlation was found between the duration of MSA and RBD ( $\mathrm{p}=0.004)$ without any other correlations of each with the neuropsychological, affective results or sleep variables. IADL negative correlated with UMSARS $(\mathrm{p}=0.002)$.

\section{Findings on VPSG}

No significant differences were found comparing T1 and T0 all VPSG parameters. Nevertheless, the following findings were detected (table 4):

Sleep Structure. Sleep efficiency was reduced (n.v. $>85 \%$ ) and REM latency increased (n.v. 60-90 min). Sleep structure was characterized by a slight increase of NREM sleep stages 1-2 (n.v. 45-55\%).

Sleep-Related Complaints. Eighty percent of patients complained about sleep fragmentation at T0 and T1. Excessive daytime sleepiness was not referred to by patients and Epworth Sleepiness Scale was within normal limits in all patients.

Respiratory Abnormalities. Snoring was detected in 3 out of 10 patients and paradoxical breathing in 6 out of 10 . Only in 2 patients, the apnea index was higher than 10 compatible with a diagnosis of OSAS. Stridor was detected in 7 out of 10 patients. For the whole group of patients, mean $\mathrm{SaO}_{2}$ throughout sleep remained at $93 \%$, with the lowest mean values at $89 \%$.

PLMS. PLMS were present in all patients and 9 out of 10 patients showed PLMS index $>10$.

$R B D$. All patients had a history of RBD that preceded the onset of the disease in 6 out of 10 (range: 1-3 years, respect the onset of the disease), coincided with the onset in 2 and followed in 2 ( 4 and 7 years after the onset). All patients showed continuous EMG activity and repetitive motor unit potential discharges in the submental mylohyoideus muscle while awake and when asleep, with phasic or tonic increase during REM sleep. RBD in the form of complex motor behaviors such as limb and body jerks or complex vigorous movements was recorded in 9 out of 10 patients.

\section{Discussion}

\section{Neuropsychological and Affective Findings}

At the first evaluation, the majority of our ten patients did not show any cognitive deficits, while only three had selective deficits (two patients in long-term verbal memory and one in visuo-spatial tasks). However, the clinical, behavioral and functional autonomy data did not indi- 
Table 3. Neuropsychological, affective and functional evaluation (mean \pm SD)

\begin{tabular}{|c|c|c|}
\hline Test & T0 & $\mathrm{T} 1$ \\
\hline MMSE & $28.10 \pm 2.07$ & $28.26 \pm 1.73$ \\
\hline Brief mental deterioration battery final result & $2.23 \pm 0.93$ & $2.46 \pm 1.02$ \\
\hline \multicolumn{3}{|l|}{ Rey's 15 Words } \\
\hline Immediate recall & $45.4 \pm 10.64$ & $47.42 \pm 10.28$ \\
\hline Delayed recall & $9.08 \pm 3.06$ & $9.82 \pm 3.59$ \\
\hline \multicolumn{3}{|l|}{ Barrage Test } \\
\hline Time & $56.4 \pm 24.2$ & $61 \pm 32.5$ \\
\hline Score & $12.2 \pm 1.03$ & $10.4 \pm 1.77^{*}$ \\
\hline Errors & $0.1 \pm 0.31$ & $0.3 \pm 0.67$ \\
\hline Result & $-0.22 \pm 0.88$ & $0.3 \pm 1.82$ \\
\hline Copy Design simple & $11.17 \pm 1.04$ & $9.8 \pm 2.89$ \\
\hline Immediate Visual Memory & $20.3 \pm 2.03$ & $20.8 \pm 1.29$ \\
\hline Analogies & $18.4 \pm 1.32$ & $18.6 \pm 2.02$ \\
\hline \multicolumn{3}{|l|}{ Verbal Fluency } \\
\hline Phonemic & $30.29 \pm 8.05$ & $26.12 \pm 7.35$ \\
\hline Semantic & $48.1 \pm 6.38$ & $44.2 \pm 7.33$ \\
\hline \multicolumn{3}{|l|}{ Stroop Test } \\
\hline Time & $16.16 \pm 7.4$ & $23.34 \pm 28.03$ \\
\hline Errors & $-0.4 \pm 0.68$ & $0.28 \pm 1.5$ \\
\hline \multicolumn{3}{|l|}{ Rey-Osterrieth Complex Figure Test } \\
\hline Direct copy & $33.3 \pm 6.38$ & $29.42 \pm 9.71$ \\
\hline Delayed recall & $17.67 \pm 3.97$ & $16.57 \pm 5.63$ \\
\hline Digit Span Forward & $6.28 \pm 1.18$ & $6.18 \pm 1.08$ \\
\hline Corsi Block-tapping Test & $5.96 \pm 1.04$ & $5.56 \pm 1.19$ \\
\hline \multicolumn{3}{|l|}{ Trail Making Test } \\
\hline A & $35.5 \pm 17.87$ & $60.75 \pm 43.82^{* *}$ \\
\hline $\mathrm{B}$ & $62.45 \pm 48.17$ & $93.15 \pm 76.7$ \\
\hline $\mathrm{B}-\mathrm{A}$ & $27 \pm 41.04$ & $31.85 \pm 35.85$ \\
\hline Paired-associated word learning test & $13.22 \pm 5.65$ & $12.7 \pm 4.37$ \\
\hline Judgment of line orientation test & $26 \pm 5.22$ & $25.30 \pm 4.99$ \\
\hline Raven colored progressive matrices & $31.16 \pm 4.19$ & $31.40 \pm 5.14$ \\
\hline \multicolumn{3}{|l|}{ Test di Intelligenza Breve } \\
\hline IQ verbal & $107.2 \pm 9.5$ & $107.2 \pm 9.5$ \\
\hline IQ performance & $109.6 \pm 8.55$ & $109.6 \pm 8.55$ \\
\hline IQ global & $108.7 \pm 9.63$ & $108.7 \pm 9.63$ \\
\hline \multicolumn{3}{|l|}{ Wisconsin Card Sorting Test } \\
\hline Perseverations & $5.3 \pm 8.32$ & $1.67 \pm 4.9$ \\
\hline Non-perseverative errors & $6.12 \pm 4.2$ & $5.28 \pm 4.32$ \\
\hline Failure to maintain the set & $0.7 \pm 2.21$ & $0.6 \pm 1.57$ \\
\hline Global score & $18.34 \pm 21.53$ & $11.48 \pm 21.17$ \\
\hline \multicolumn{3}{|l|}{ State and Trait Anxiety Inventory-Y } \\
\hline State & $49.6 \pm 8.59$ & $51.6 \pm 11.38$ \\
\hline Trait & $50.1 \pm 9.08$ & $53.2 \pm 8.5$ \\
\hline Beck Depression Inventory & $12.3 \pm 7.33$ & $14.2 \pm 7.56$ \\
\hline Epworth scale & $5.3 \pm 2.7$ & $4.9 \pm 3.1$ \\
\hline Activities of daily living (ADLs) & $5.6 \pm 0.69$ & $4.8 \pm 1.31^{*}$ \\
\hline Instrumental activities of daily living (IADLs) & $5.2 \pm 1.61$ & $4.1 \pm 2.07^{* *}$ \\
\hline Unified multiple system atrophy Rating Scale (UMSARS) & $19.8 \pm 4.54$ & $28.3 \pm 6.91^{* * *}$ \\
\hline
\end{tabular}

${ }^{*} \mathrm{p}=0.02 ;^{* *} \mathrm{p}=0.01 ;{ }^{* * *} \mathrm{p}=0.005$. 
Table 4. Video-polysomnographic recordings at T0

\begin{tabular}{|c|c|c|c|c|c|c|c|c|c|c|c|}
\hline Sleep parameters & $\begin{array}{l}\text { Pt. } 1 \\
\text { MSA-C }\end{array}$ & $\begin{array}{l}\text { Pt. } 2 \\
\text { MSA-P }\end{array}$ & $\begin{array}{l}\text { Pt. } 3 \\
\text { MSA-C }\end{array}$ & $\begin{array}{l}\text { Pt. } 4 \\
\text { MSA-P }\end{array}$ & $\begin{array}{l}\text { Pt. } 5 \\
\text { MSA-C }\end{array}$ & $\begin{array}{l}\text { Pt. } 6 \\
\text { MSA-C }\end{array}$ & $\begin{array}{l}\text { Pt. } 7 \\
\text { MSA-P }\end{array}$ & $\begin{array}{l}\text { Pt. } 8 \\
\text { MSA-P }\end{array}$ & $\begin{array}{l}\text { Pt. } 9 \\
\text { MSA-C }\end{array}$ & $\begin{array}{l}\text { Pt. } 10 \\
\text { MSA-C }\end{array}$ & Mean \pm SD \\
\hline Total sleep time, min & 312 & 249 & 341 & 293 & 194 & 291 & 283 & 335 & 343 & 215 & $285.6 \pm 51.96$ \\
\hline $1, \%$ & 4 & 5 & 3 & 6 & 6 & 20 & 7 & 2 & 16 & 3 & 7.2 \\
\hline $2, \%$ & 40 & 43 & 27 & 72 & 35 & 56 & 56 & 42 & 51 & 41 & 46.3 \\
\hline WASO (\%) & 13 & 18 & 11 & 23 & 48 & 30 & 22 & 17 & 21 & 43 & 24.6 \\
\hline Sleep latency, min & 24 & 14 & 10 & 15 & 25 & 22 & 47 & 2 & 2 & 12 & $17.3 \pm 13.22$ \\
\hline REM latency, min & 74 & 95 & 56 & 140 & 120 & 135 & 114 & 67 & 21 & 254 & $107.6 \pm 63.7$ \\
\hline PLMS index & 79 & 191 & 11 & 10 & 105 & 134 & 10 & 101 & 5 & 6 & $65.2 \pm 66.47$ \\
\hline Arousal index & 7 & 6 & 7 & 20 & 7 & 6 & 8 & 13 & 10 & 6 & $9 \pm 4.44$ \\
\hline
\end{tabular}

cate the presence of dementia in any of our patients. Also considering the follow-up, after a mean of 16 months, cognitive performance of all patients remained unchanged, except for one of the seven previously not impaired who developed multiple cognitive deficits. Nevertheless, the global cognitive indexes of this patient were still within normal limits; therefore, he should not be considered demented. The significant worsening of ADL/IADL of the entire group between $\mathrm{T} 0$ and $\mathrm{T} 1$ could be related to a motor impairment increase. We did not find significant differences in cognitive performance between MSA-P and MSA-C patients, according to recent findings [17].

Depression was present in half of our MSA patients as in the Kao et al. study [8]. Since depression was present both in patients with or without cognitive deficits, and neither were there differences between cognitive performance in depressed and not-depressed patients nor a significant worsening from $\mathrm{T} 0$ to $\mathrm{T} 1$, its effective role on cognition is probably marginal as recently supposed by others [17].

To our knowledge, only a study [6], analyzed the longitudinal follow-up of cognitive functions in MSA, evaluating for a mean of 21 months, 14 striatonigral degeneration patients classified by Quinn's criteria [36]. These authors disclosed a verbal fluency deficit at the first examination and a significant worsening on a visual search test at the follow-up. No patients were clearly demented during both the evaluations.

In our study, comparing the cognitive results between $\mathrm{T} 0$ and $\mathrm{T} 1$, a significant worsening was found in two tests exploring attention (Barrage Test score and Trail Making Test-A), while global cognitive indexes or tests exploring other cognitive domains, showed no significant difference. Although Barrage Test and Trail Making Test mainly explore attention, other cognitive functions such as ability to inhibit contrasting responses, speed of cognitive processing and visual searching capacity are implied. However, it's noteworthy that results at the Wisconsin Card Sorting Test, which explores the cognitive flexibility, which is an aspect of executive functions, were within normal limits in all our patients at both evaluations. Thus, it's conceivable that a selective deficit of attention may occur in a minority of MSA patients, especially along the evolution of the disease. A longer follow-up of our patients should allow a more detailed characterization of their cognitive evolution; nevertheless, the dramatic worsening of motor and dysautonomic functions, often makes very difficult, if not impossible, to perform the formal neuropsychological assessment.

\section{Sleep Structure, Sleep-Related Respiratory \\ Abnormalities and PLMS}

Polygraphic data of our patients confirmed a reduced sleep efficiency, slight increase of the NREM stages, and increase of REM latency without significant difference between the first and the second polygraphic recordings. Our patients showed a frequency of stridor and OSA comparable with those previous reported, respectively of 70 and $20 \%$, with a mild O2 desaturation. PLMS are significantly increased as reported in literature [43$45,47]$. 


\section{$R B D$}

In idiopathic $\mathrm{RBD}$, visuoconstructional and visuospatial deficits had been detected with a pattern similar to the neuropsychological profile of LBD [3-5]. In our sample, RBD preceded the onset of the disease in 6 patients (four who showed cognitive deficits and two who were cognitive normal). Visuoconstructional and visuospatial deficits were found only in two and a uniform neuropsychological profile was not detected. Moreover, as in idiopathic RBD [3], in our patients, the RBD duration did not correlate with the neuropsychological performance. Overall, considering these data in our small MSA sample, we found that RBD does not correlate with the neuropsychological findings and this disorder, although present in all our patients, does not appear as a clear early marker of cognitive impairment. Future longer-term studies with a larger patient sample are thus encouraged.

\section{References}

1 Gilman S, Wenning GK, Low PA, Brooks DJ, Mathias CJ, Trojanowski JQ, Wood NW, Colosimo C, Dürr A, Fowler CJ, Kaufmann H, Klockgether T, Lees A, Poewe W, Quinn N, Revesz T, Robertson D, Sandroni P, Seppi K, Vidailhet M: Second consensus statement on the diagnosis of multiple system atrophy. Neurology 2008;71:670-676.

$\checkmark 2$ Gilman S, Low PA, Quinn N, Albanese A, Ben-Shlomo Y, Fowler CJ, Kaufmann H, Klockgether T, Lang AE, Lantos PL, Litvan I, Mathias CJ, Oliver E, Robertson D, Schatz I, Wenning GK: Consensus statement on the diagnosis of multiple system atrophy. J Neurol Sci 1999;163:94-98.

-3 Ferini-Strambi L, Di Gioia MR, Castronovo V, Oldani A, Zucconi M, Cappa SF: Neuropsychological assessment in idiopathic REM sleep behavior disorder (RBD): does the idiopathic form of RBD really exist? Neurology 2004;62:41-45.

4 Boeve BF, Silber MH, Ferman TJ, Kokmen E, Smith GE, Ivnik RJ, Parisi JE, Olson EJ, Petersen RC: REM sleep behavior disorder and degenerative dementia: an association likely reflecting Lewy body disease. Neurology 1998;51:363-370.

5 Terzaghi M, Sinforiani E, Zucchella C, Zambrelli E, Pasotti C, Rustioni V, Manni R: Cognitive performance in REM sleep behaviour disorder: a possible early marker of neurodegenerative disease? Sleep Med 2008;9:343-351.

-6 Soliveri P, Monza D, Paridi D, Carella F, Genitrini S, Testa D, Girotti F: Neuropsychological follow up in patients with Parkinson's disease, striatonigral degeneration-type multisystem atrophy, and progressive supranuclear palsy. J Neurol Neurosurg Psychiatry 2000;69:313-318.

7 Brown RG, Lacomblez L, Landwehrmeyer BG, Bak T, Uttner I, Dubois B, Agid Y, Ludolph A, Bensimon G, Payan C, Leigh NP; NNIPPS Study Group: Cognitive impairment in patients with multiple system atrophy and progressive supranuclear palsy. Brain 2010; 133:2382-2393.

$\checkmark 8$ Kao AW, Racine CA, Quitania LC, Kramer JH, Christine CW, Miller BL: Cognitive and neuropsychiatric profile of the synucleinopa- thies: Parkinson disease, dementia with Lewy bodies, and multiple system atrophy. Alzheimer Dis Assoc Disord 2009;23:365-370.

-9 Bak TH, Caine D, Hearn VC, Hodges JR: Visuospatial functions in atypical parkinsonian syndromes. J Neurol Neurosurg Psychiatry 2006;77:454-456.

10 Krishnan S, Mathuranath PS, Sarma S, Kishore A: Neuropsychological functions in progressive supranuclear palsy, multiple system atrophy and Parkinson's disease. Neurol India 2006;54:268-272.

11 Bak TH, Crawford LM, Hearn VC, Mathuranath PS, Hodges JR: Subcortical dementia revisited: similarities and differences in cognitive function between progressive supranuclear palsy (PSP), corticobasal degeneration (CBD) and multiple system atrophy (MSA). Neurocase 2005;11:268-273.

$\checkmark 12$ Bak TH, Rogers TT, Crawford LM, Hearn VC, Mathuranath PS, Hodges JR: Cognitive bedside assessment in atypical parkinsonian syndromes. J Neurol Neurosurg Psychiatry 2005;76:420-422.

13 Meco G, Gasparini M, Doricchi F: Attentional functions in multiple system atrophy and Parkinson's disease. J Neurol Neurosurg Psychiatry 1996;60:393-398.

14 Pillon B, Gouider-Khouja N, Deweer B, Vidailhet M, Malapani C, Dubois B, Agid Y: Neuropsychological pattern of striatonigral degeneration: comparison with Parkinson's disease and progressive supranuclear palsy. J Neurol Neurosurg Psychiatry 1995;58:174-179.

15 Robbins TW, James M, Owen AM, Lange KW, Lees AJ, Leigh PN, Marsden CD, Quinn NP, Summers BA: Cognitive deficits in progressive supranuclear palsy, Parkinson's disease, and multiple system atrophy in tests sensitive to frontal lobe dysfunction. J Neurol Neurosurg Psychiatry 1994;57:79-88.

16 Kim HJ, Jeon BS, Kim YE, Kim JY, Kim YK, Sohn CH, Yun JY, Jeon S, Lee JM, Lee JY: Clinical and imaging characteristics of dementia in multiple system atrophy. Parkinsonism Relat Disord 2013;19:617-621.

17 Siri C, Duerr S, Canesi M, Delazer M, Esselink R, Bloem BR, Gurevich T, Balas M, Giladi N, Santacruz P, Marti F, Tolosa E, Rubino A,
Meco G, Poewe W, Pezzoli G, Wenning G, Antonini A: A cross-sectional multicenter study of cognitive and behavioural features in multiple system atrophy patients of the parkinsonian and cerebellar type. J Neural Transm 2013;120:613-618.

18 Spaccavento S, Del Prete M, Loverre A, Craca A, Nardulli R: Multiple system atrophy with early cognitive deficits: a case report. Neurocase 2013;19:613-622.

19 Balas M, Balash Y, Giladi N, Gurevich T: Cognition in multiple system atrophy: neuropsychological profile and interaction with mood. J Neural Transm 2010;117:369-375.

20 Schrag A, Sheikh S, Quinn NP, Lees AJ, Selai C, Mathias C, Litvan I, Lang AE, Bower JH, Burn DJ, Low P, Jahanshahi M: A comparison of depression, anxiety, and health status in patients with progressive supranuclear palsy and multiple system atrophy. Mov Disord 2010;25:1077-1081.

21 Kawamura K, Shimohata T, Nakayama H, Tomita M, Ozawa T, Nishizawa M: Factors influencing the cognitive function in patients with multiple system atrophy. Mov Disord 2010;25:2891-2892.

22 Kitayama M, Wada-Isoe K, Irizawa Y, Nakashima K: Assessment of dementia in patients with multiple system atrophy. Eur J Neurol 2009; 16:589-594.

23 Chang CC, Chang YY, Chang WN, Lee YC, Wang YL, Lui CC, Huang CW, Liu WL: Cognitive deficits in multiple system atrophy correlate with frontal atrophy and disease duration. Eur J Neurol 2009;16:1144-1150.

24 Kawai Y, Suenaga M, Takeda A, Ito M, Watanabe H, Tanaka F, Kato K, Fukatsu H, Naganawa S, Kato T, Ito K, Sobue G: Cognitive impairments in multiple system atrophy: MSAC vs MSA-P. Neurology 2008;70:1390-1396.

25 Lyoo CH, Jeong Y, Ryu YH, Lee SY, Song TJ, Lee JH, Rinne JO, Lee MS: Effects of disease duration on the clinical features and brain glucose metabolism in patients with mixed type multiple system atrophy. Brain 2008;131: 438-446.

26 Bürk K, Daum I, Rüb U: Cognitive function in multiple system atrophy of the cerebellar type. Mov Disord 2006;21:772-776. 
-27 Paviour DC, Winterburn D, Simmonds S, Burgess G, Wilkinson L, Fox NC, Lees AJ, Jahanshahi M: Can the frontal assessment battery $(\mathrm{FAB})$ differentiate bradykinetic rigid syndromes? Relation of the FAB to formal neuropsychological testing. Neurocase 2005; 11:274-282.

28 Lange KW, Tucha O, Alders GL, Preier M, Csoti I, Merz B, Mark G, Herting B, Fornadi F, Reichmann H, Vieregge P, Reiners K, Becker G, Naumann M: Differentiation of parkinsonian syndromes according to differences in executive functions. J Neural Transm 2003; 110:983-995.

29 Berent S, Giordani B, Gilman S, Trask CL, Little RJ, Johanns JR, Junck L, Kluin KJ, Heumann M, Koeppe RA: Patterns of neuropsychological performance in multiple system atrophy compared to sporadic and hereditary olivopontocerebellar atrophy. Brain Cogn 2002;50:194-206.

30 Monza D, Soliveri P, Radice D, Fetoni V, Testa D, Caffarra P, Caraceni T, Girotti F: Cognitive dysfunction and impaired organization of complex motility in degenerative parkinsonian syndromes. Arch Neurol 1998;55:372-378.

- 31 Robbins TW, James M, Lange KW, Owen AM, Quinn NP, Marsden CD: Cognitive performance in multiple system atrophy. Brain 1992;115:271-291.

- 32 Testa D, Fetoni V, Soliveri P, Musicco M, Palazzini E, Girotti F: Cognitive and motor performance in multiple system atrophy and Parkinson's disease compared. Neuropsychologia 1993;31:207-210.

-33 Sullivan EV, De La Paz R, Zipursky RB, Pfefferbaum A: Neuropsychological deficits accompanying striatonigral degeneration. I Clin Exp Neuropsychol 1991;13:773-788.

- 34 Wenning GK, Ben-Shlomo Y, Hughes A, Daniel SE, Lees A, Quinn NP: What clinical features are most useful to distinguish definite multiple system atrophy from Parkinson's disease? J Neurol Neurosurg Psychiatry 2000; 68:434-440.

- 35 O’Sullivan SS, Massey LA, Williams DR, Silveira-Moriyama L, Kempster PA, Holton JL, Revesz T, Lees AJ: Clinical outcomes of progressive supranuclear palsy and multiple system atrophy. Brain 2008;131:13621372.

36 Quinn N: Multiple system atrophy-the nature of the beast. J Neurol Neurosurg Psychiatry 1989;20:78-89.

- 37 Poda R, Guaraldi P, Solieri L, Calandra-Buonaura G, Marano G, Gallassi R, Cortelli P: Standing worsens cognitive functions in patients with neurogenic orthostatic hypotension. Neurol Sci 2012;33:469-473.

- 38 Peralta C, Stampfer-Kountchev M, Karner E, Köllensperger M, Geser F, Wolf E, Seppi K, Benke T, Poewe W, Wenning GK: Orthostatic hypotension and attention in Parkinson's disease with and without dementia. J Neural Transm 2007;114:585-588.

-39 Allcock LM, Kenny RA, Mosimann UP, Tordoff S, Wesnes KA, Hildreth AJ, Burn DJ:
Orthostatic hypotension in Parkinson's disease: association with cognitive decline? Int J Geriatr Psychiatry 2006;21:778-783.

40 Ghorayeb I, Yekhlef F, Chrysostome V, Balestre E, Bioulac B, Tison F: Sleep disorders and their determinants in multiple system atrophy. J Neurol Neurosurg Psychiatry 2002; 72:798-800.

41 Ghorayeb I, Bioulac B, Tison F: Sleep disorders in multiple system atrophy. J Neural Transm 2005;112:1669-1675.

42 Moreno-López C, Santamaría J, Salamero M, Del Sorbo F, Albanese A, Pellecchia MT, Barone P, Overeem S, Bloem B, Aarden W, Canesi M, Antonini A, Duerr S, Wenning GK, Poewe W, Rubino A, Meco G, Schneider SA, Bhatia KP, Djaldetti R, Coelho M, Sampaio C, Cochen V, Hellriegel H, Deuschl G, Colosimo C, Marsili L, Gasser T, Tolosa E: Excessive daytime sleepiness in multiple system atrophy (SLEEMSA study). Arch Neurol 2011;68: 223-230.

$43 \mathrm{Nam} \mathrm{H}$, Hong YH, Kwon HM, Cho J: Does multiple system atrophy itself affect sleep structure? Neurologist 2009;15:274-276.

44 Vetrugno R, Provini F, Cortelli P, Plazzi G, Lotti EM, Pierangeli G, Canali C, Montagna $\mathrm{P}$ : Sleep disorders in multiple system atrophy: a correlative video-polysomnographic study. Sleep Med 2004;5:21-30.

45 Wetter TC, Collado-Seidel V, Pollmächer T, Yassouridis A, Trenkwalder C: Sleep and periodic leg movement patterns in drugfree patients with Parkinson's disease and multiple system atrophy. Sleep 2000;23: 361-367.

46 Plazzi G, Corsini R, Provini F, Pierangeli G, Martinelli P, Montagna P, Lugaresi E, Cortelli P: REM sleep behavior disorders in multiple system atrophy. Neurology 1997;48:10941097.

47 Manni R, Morini R, Martignoni E, Pacchetti C, Micieli G, Tartara A: Nocturnal sleep in multisystem atrophy with autonomic failure: polygraphic findings in ten patients. J Neurol 1993;240:249-250.

48 Vetrugno R, D’Angelo R, Cortelli P, Plazzi G, Vignatelli L, Montagna P: Impaired cortical and autonomic arousal during sleep in multiple system atrophy. Clin Neurophysiol 2007; 118:2512-2518.

49 Yamaguchi M, Arai K, Asahina M, Hattori T: Laryngeal stridor in multiple system atrophy. Eur Neurol 2003;49:154-159.

50 Wenning GK, Tison F, Ben Shlomo Y, Daniel SE, Quinn NP: Multiple system atrophy: a review of 203 pathologically proven cases. Mov Disord 1997;12:133-147.

51 Vetrugno R, Alessandria M, D'Angelo R, Plazzi G, Provini F, Cortelli P, Montagna P: Status dissociatus evolving from REM sleep behaviour disorder in multiple system atrophy. Sleep Med 2009;10:247-252.

52 Tachibana N, Kimura K, Kitajima K, Shinde A, Kimura J, Shibasaki H: REM sleep motor dysfunction in multiple system atrophy: with special emphasis on sleep talk as its early clin- ical manifestation. J Neurol Neurosurg Psychiatry 1997;63:678-681.

53 Claassen DO, Josephs KA, Ahlskog JE, Silber MH, Tippmann-Peikert M, Boeve BF: REM sleep behavior disorder preceding other aspects of synucleinopathies by up to half a century. Neurology 2010;75:494-499.

-54 Tison F, Wenning GK, Quinn NP, Smith SJ: REM sleep behaviour disorder as the presenting symptom of multiple system atrophy. J Neurol Neurosurg Psychiatry 1995;58:379380.

55 Schenck CH, Boeve BF, Mahowald MW: Delayed emergence of a parkinsonian disorder or dementia in $81 \%$ of older males initially diagnosed with idiopathic REM sleep behavior disorder (RBD): 16 year update on a previously reported series. Sleep Med 2013;14: 744-748.

56 Iranzo A, Tolosa E, Gelpi E, Molinuevo JL, Valldeoriola F, Serradell M, Sanchez-Valle R, Vilaseca I, Lomeña F, Vilas D, Lladó A, Gaig C, Santamaria J: Neurodegenerative disease status and post-mortem pathology in idiopathic rapid-eye-movement sleep behaviour disorder: an observational cohort study. Lancet Neurol 2013;12:443-453.

57 Iranzo A, Santamaría J, Rye DB, Valldeoriola F, Martí MJ, Muñoz E, Vilaseca I, Tolosa E: Characteristics of idiopathic REM sleep behavior disorder and that associated with MSA and PD. Neurology 2005;65:247-252.

58 Wenning GK, Tison F, Seppi K, Sampaio C, Diem A, Yekhlef F, Ghorayeb I, Ory F, Galitzky M, Scaravilli T, Bozi M, Colosimo C, Gilman S, Shults CW, Quinn NP, Rascol O, Poewe W; Multiple System Atrophy Study Group: Development and validation of the Unified Multiple System Atrophy Rating Scale (UMSARS). Mov Disord 2004;19:13911402.

59 Ferracuti S, Cannoni E, Sacco R, Hufty AM: Contributi per un assessment neuropsicologico. Manuale Clinico. Giunti Organizzazioni Speciali, Firenze, 2007.

60 Colombo L, Sartori G, Brivio C: Stima del quoziente intellettivo tramite l'applicazione del TIB (Test di Intelligenza Breve). Giornale Italiano di Psicologia 2002;3:613-638.

61 Caffarra P, Vezzadini G, Dieci F, et al: Una versione abbreviata del test di Stroop: dati normativi nella popolazione italiana. Nuova Rivista di Neurologia 2002;12:111-115.

62 Caffarra P, Vezzadini G, Dieci F, Zonato F, Venneri A: Rey-Osterrieth complex figure: normative values in an Italian population sample. Neurol Sci 2002;22:443-447.

63 Laiacona M, Inzaghi MG, De Tanti A, Capitani E: Wisconsin card sorting test: a new global score, with Italian norms, and its relationship with the Weigl sorting test. Neurol Sci 2000;21:279-291.

64 Giovagnoli AR, Del Pesce M, Mascheroni S, Simoncelli M, Laiacona M, Capitani E: Trail making test: normative values from 287 normal adult controls. Ital J Neurol Sci 1996;17: 305-309. 
65 Spinnler H, Tognoni G: Standardizzazione e taratura italiana di test neuropsicologici. Ital J Neurol Sci 1987;6(suppl 8):1-120.

-66 Orsini A, Grossi D, Capitani E, Laiacona M, Papagno C, Vallar G: Verbal and spatial immediate memory span: normative data from 1355 adults and 1112 children. Ital J Neurol Sci 1987;8:539-548.

67 Novelli G, Papagno C, Capitani E, et al: Tre test clinici di ricerca e produzione lessicale. Taratura su soggetti normali. Archivio di Psicologia, Neurologia e Psichiatria 1986;47: 279-296.

68 De Renzi E, Faglioni P, Ruggerini C: Prove di memoria verbale d'impiego clinico per la diagnosi di amnesia. Archivio di Psicologia, Neurologia e Psichiatria 1977;3:303-318.

69 Folstein MF, Folstein SE, McHugh PR: 'Mini Mental State': a practical method for grading the cognitive state of patients for the clinician. J Psychiatr Res 1975;12:189-198.
70 Measso G, Cavarzeran F, Zappalà G, et al: The Mini-Mental State Examination: normative study of an Italian random sample. Dev Neuropsychol 1993;9:77-85.

71 Gallassi R, Oppi F, Poda R, Scortichini S, Stanzani Maserati M, Marano G, Sambati L: Are subjective cognitive complaints a risk factor for dementia? Neurol Sci 2010;31:327336.

72 Gallassi R, Lenzi P, Stracciari A, Lorusso S, Ciardulli C, Morreale A, Mussuto V: Neuropsychological assessment of mental deterioration: purpose of a brief battery and a probabilistic definition of 'normality' and 'nonnormality'. Acta Psychiatr Scan 1986;75: 62-67.

73 Beck AT, Ward CH, Mendelson M, Mock J, Erbaugh J: An inventory for measuring depression. Arch Gen Psychiatry 1961;45:561571.
74 Spielberger CD, Vagg PR, Barker LR, et al: The factor structure of the State-Trait Anxiety Inventory; in Sarason IG, Spielberger CD (eds): Stress and Anxiety. Hemisphere/Wiley, New York, 1980, pp 95-109.

75 Iber C, Ancoli-Israel S, Chesson A, Quan SF: The AASM manual for the scoring of sleep and associated events: rules, terminology and technical specifications. IL: American Academy of Sleep Medicine, Westchester, 2007.

76 International Classification of Sleep Disorders. Diagnostic \& Coding Manual, ed 2. IL: American Academy of Sleep Medicine, Westchester, 2005

-77 Vignatelli L, Plazzi G, Barbato A, FeriniStrambi L, Manni R, Pompei F, D’Alessandro R; GINSEN (Gruppo Italiano Narcolessia Studio Epidemiologico Nazionale): Italian version of the Epworth sleepiness scale: external validity. Neurol Sci 2003;23:295-300. 